\title{
AVALIAÇÃO CATALÍTICA DA CTA-MCM-41 NA CONDENSAÇÃO DE KNOEVENAGEL
}

\author{
H. A. DINIZ, P. C. CUENCA e J. G. P. VICENTE \\ Faculdade de Engenharia de Sorocaba \\ e-mail para contato: joao.vicente@facens.br
}

\begin{abstract}
RESUMO - Embora muitas das reações envolvendo processos químicos sejam tipicamente catalisadas por peneiras moleculares ácidas, o uso de peneiras moleculares com propriedades básicas possui grandes vantagens sobre suas propriedades catalíticas, como estabilidade e seletividade. Sendo assim, neste trabalho, foi sintetizada e avaliada a estabilidade da peneira molecular mesoporosa CTA-MCM-41 na reação de condensação de Knoevenagel sob a presença dos solventes acetonitrila, etanol e toluol.
\end{abstract}

\section{INTRODUÇÃO}

Peneiras moleculares são sólidos porosos capazes de adsorver seletivamente moléculas cujo diâmetro cinético permite a entrada em seus canais. Quando comparado com a ampla aplicação de peneiras moleculares ácidas como catalisadores sólidos em tecnologia de processamento químico, poucos estudos têm sido realizados com os materiais com propriedades básicas, apesar do grande potencial para o uso em uma série de reações industrialmente importantes, incluindo adições aldólicas, reações de condensação e de transesterificação. (MARTINS e CARDOSO, 2006; VICENTE et al., 2016).

Entre os estudos realizados com peneiras moleculares microporosas básicas, destacamse as condensações de Claisen, de Knoevenagel, aldólicas e a transesterificação (VICENTE et al., 2015; VICENTE et al., 2016). Atualmente, entre todos os processos catalisados por sólidos ácidos, básicos e bifuncionais, apenas $8 \%$ correspondem à aplicação de materiais com propriedades básicas. As vantagens de tais peneiras devem-se a possibilidade no ajuste das propriedades catalíticas, através da alteração da composição química e por tratamentos químicos posteriores às sínteses (MARTINS e CARDOSO, 2006).

A reação de condensação de Knoevenagel (Equação 1) trata-se de uma reação modelo que tem sido aplicada para a caracterização das propriedades básicas de peneiras moleculares, cujo produto formado é constituído por moléculas complexas e com grupos funcionais específicos. Na reação há interação de um composto carbonílico (aldeídos ou cetonas) com moléculas de grupos metilênicos ativados que produzem olefinas de alto peso molecular, produto este de grande importância para as indústrias farmacêuticas e de aromas (MARTINS e CARDOSO, 2006).

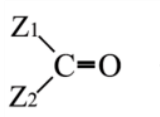

(1)

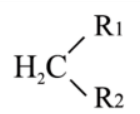

(2)

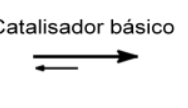<smiles>[Z]C([Z])C([10BH2])[17NH2]</smiles>

(3)
(4) 
Assim, o objetivo deste trabalho é avaliar a influência dos solventes acetonitrila, etanol e toluol na estabilidade catalítica da peneira molecular CTA-MCM-41 (tal como sintetizada) como catalisador na reação modelo de condensação de Knoevenagel entre o benzaldeído e o cianoacetato de etila.

\section{PARTE EXPERIMENTAL}

Abaixo segue a metodologia de trabalho utilizada na realização deste trabalho.

\subsection{Síntese da Sílica}

A síntese da sílica CTA-MCM-41 foi realizada a partir do método de ARAÚJO (ARAÚJO et al., 2013). A composição molar da mistura reacional foi de $1 \mathrm{SiO}_{2}: 12,5 \mathrm{NH}_{3}: 0,4 \mathrm{CTABr}: 174 \mathrm{H}_{2} \mathrm{O}$.

Primeiramente, as massas dos reagentes foram pesadas de acordo com a estequiometria acima. Em seguida, dissolveu-se o surfactante $(\mathrm{CTABr}$ - brometo de cetiltrimetilamônio) em água deionizada e adicionou-se $\mathrm{NH}_{4} \mathrm{OH}$ à mistura, mantendo-a sob agitação magnética durante $15 \mathrm{~min}$. Em seguida, adicionou-se a fonte de sílica (TEOS - ortossilicato de tetraetila) à mistura, deixando-a sob agitação a $30^{\circ} \mathrm{C}$ por um período de $120 \mathrm{~min}$. Decorrido esse tempo, o sólido obtido foi filtrado e submetido a diversas lavagens com água destilada até $\mathrm{pH} \approx 7 \mathrm{e}$ seco a $60{ }^{\circ} \mathrm{C}$ durante $24 \mathrm{~h}$.

\subsection{Caracterização}

A caracterização do sólido sintetizado foi feita pela técnica de difratometria de raios X, em um difratômetro Rigaku Mini Flex 600 com tubo de $\mathrm{Cu}$ e filtro de $\mathrm{Ni}$, operando com radiação $\mathrm{CuK} \alpha(\lambda=0,1542 \mathrm{~nm})$. A velocidade do goniômetro empregada foi $2^{\circ} 2 \theta \cdot \mathrm{min}^{-1}$, com um step de $0,02^{\circ}$. A variação no ângulo ocorreu na faixa de 1 a $10^{\circ}$.

As medidas de espectroscopia no infravermelho por transformada de Fourier (FTIR) foram realizadas em um espectrômetro da Agilent modelo Cary 630 FTIR, equipado com acessório de refletância total atenuada e um cristal de diamante. Os espectros foram coletados na faixa de comprimento de onda entre 4000 a $600 \mathrm{~cm}^{-1}$, com 256 varreduras e resolução de 2 $\mathrm{cm}^{-1}$.

\subsection{Avaliação Catalítica}

A avaliação catalítica foi realizada por meio da condensação de Knoevenagel (Equação1), a partir de uma mistura equimolar contendo $4,8 \mathrm{mmol}$ de benzaldeído (Acros 99\%) e 4,8 mmol de cianoacetato de etila (Acros 99\%), com 3\% m/m de catalisador em base na massa dos reagentes em combinação com três solventes variáveis, acetonitrila, etanol e toluol $(85 \% \mathrm{~m} / \mathrm{m}$ reagentes). Tal reação deu-se em um reator batelada encamisado com 100 $\mathrm{mL}$ de capacidade volumétrica, com circulação de água a $50{ }^{\circ} \mathrm{C}$ e com agitação magnética constante. Alíquotas da mistura reacioal foram coletadas para os tempos de $0,2,5,10,15,30$ e 60 minutos e centrifugadas a $3400 \mathrm{rpm}$ para a separação das fases. 
O produto da reação foi analisado por um cromatógrafo gasoso SHIMADZU modelo GC 2010 com detector de ionizaçao de chama e coluna capilar HP-1 de 30,0 m de comprimento, 0,32 $\mathrm{mm}$ de diâmetro e filme com espessura de $3 \mu \mathrm{m}$. Para separação dos reagentes e do produto a coluna foi mantida nas seguintes condições: $180{ }^{\circ} \mathrm{C}$ por 4,3 min e $250^{\circ} \mathrm{C}$ por 13,0 min; utilizando nitrogênio como gás de arraste.

\subsection{Estabilidade Catalítica}

A estabilidade do catalisador foi determinada por meio de três reusos na reação de Knoevenagel. Após cada reação, os catalisadores foram lavados com benzeno e depois secos em estufa a $60^{\circ} \mathrm{C}$.

\section{RESULTADOS E DISCUSSÃO}

A Figura 1.a apresenta o difratograma de raios-X da amostra de sílica sintetizada. A

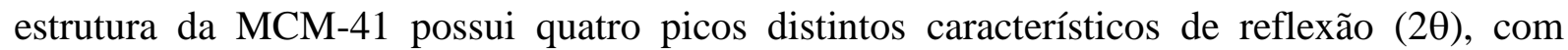

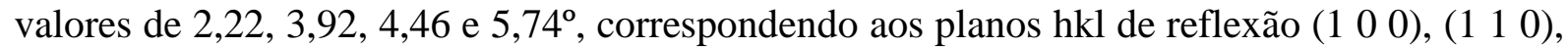
(2 00 ) e (2 10 ), respectivamente (OLIVEIRA et al., 2009).

A Figura 1.b apresenta o espectro obtido pelo FTIR. As bandas em torno de 3400 e $1630 \mathrm{~cm}^{-1}$ são atribuídas ao estiramento e deformação da ligação $\mathrm{O}-\mathrm{H}$ da água, respectivamente. As bandas em 2923 e $2853 \mathrm{~cm}^{-1}$ são relativas aos estiramentos $\mathrm{C}-\mathrm{H}$ de grupos $\mathrm{CH}_{3}$ e $\mathrm{CH}_{2}$ do agente direcionador, a banda em $1476 \mathrm{~cm}^{-1}$ refere-se à deformação $\mathrm{H}$ C-H dos ramos orgânicos. Na região entre 1400 e $600 \mathrm{~cm}^{-1}$, situam-se as bandas referentes às vibrações fundamentais da MCM-41, as principais bandas estão situadas em $1200 \mathrm{~cm}^{-1}$ (estiramentos assimétricos $\rightarrow \mathrm{Si}-\mathrm{O}$ ), $1020 \mathrm{~cm}^{-1}$ (estiramentos assimétricos $\rightarrow \mathrm{Si}-\mathrm{O}-\mathrm{Si}$ ), 780 $\mathrm{cm}^{-1}$ (estiramentos simétricos $\rightarrow \mathrm{Si}-\mathrm{O}$ ) e $954 \mathrm{~cm}^{-1}$ (estiramento $\mathrm{Si}-\mathrm{O} \rightarrow$ presentes em grupos Si-OH) (CHEN et al., 1993; COSTA et al., 2014; LAGHAEI et al., 2016; ZHAO et al., 1997).

Figura 1 - Difratograma de raios-X (a) e espectro de FTIR (b) da CTA-MCM-41.

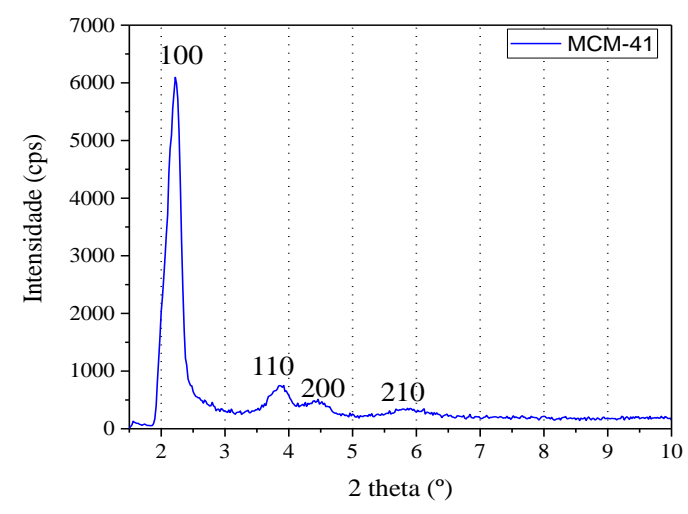

(a)

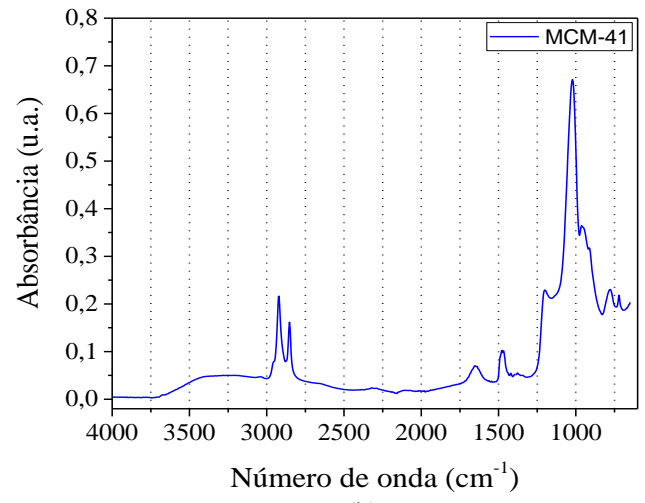

(b)

Diante de tais resultados, é possível afirmar que o catalisador que será utilizado nas etapas seguintes, refere-se à estrutura mesoporosa MCM-41. Para avaliar a atividade catalítica da CTA-MCM-41 na condensação de Knoevenagel entre o benzaldeído e cianoacetato de etila na presença de três solventes diferentes (acetonitrila, etanol e toluol), realizou-se o estudo 
cinético da conversão do benzaldeído em função do tempo. Ao avaliar as conversões obtidas na Figura 2a, observa-se que o solvente empregado afeta diretamente na atividade catalítica.

Os melhores resultados obtidos quando o etanol é adicionado como solvente ao meio reacional, pode estar relacionado ao fato do EtOH ser um solvente com caráter polar anfiprótico, ou seja, o álcool etílico atua como doador e receptor de prótons. Por este comportamento, a reação pode ser favorecida pela ativação do grupo metilênico do cianoacetato de etila e pela polarização do grupo carbonílico do benzaldeído, portanto maiores conversões são alcançadas (CHAVES et al., 2016).

Visando verificar a relação existente entre a influência da substituição do solvente na condensação de Knoevenagel e a estabilidade catalítica da CTA-MCM-41, realizou-se o ensaio de estabilidade mediante a realização de três usos (Figura 2.b). É possível verificar através dos resultados de conversão do benzaldeído em função do uso que independentemente do solvente utilizado, uma perda na atividade catalítica da CTA-MCM-41 é decorrente.

Figura 2 - Conversões do benzaldeído frente à reação de condensação de Knoevenagel (a), estudo cinético e (b) estabilidade catalítica.

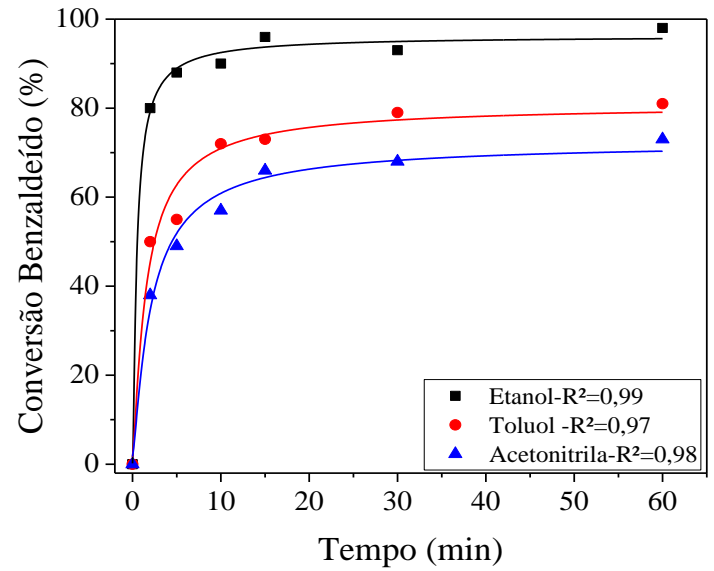

(a)

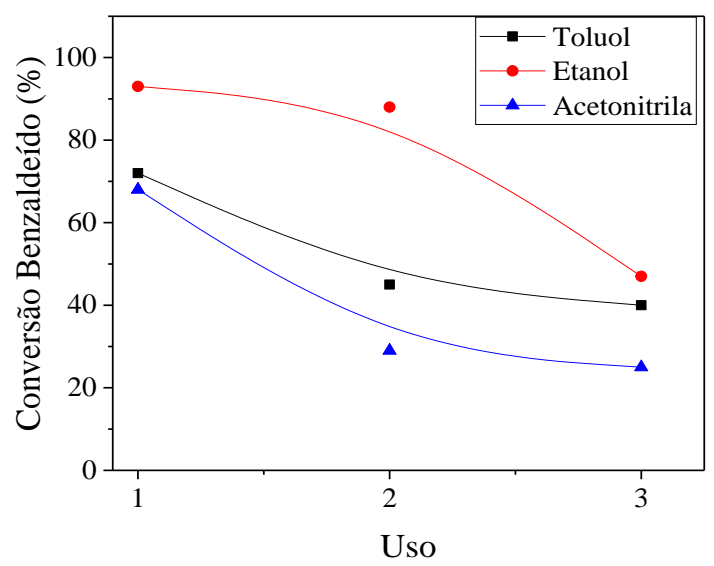

(b)

Essa perda na atividade catalítica ao decorrer dos usos está associada à lixiviação dos cátions orgânicos para o meio reacional, estes cátions lixiviados encontram-se fracamente ligados às micelas localizadas na boca dos poros ou na superfície da sílica. Baseado nesta teoria, após o primeiro uso do catalisador a quantidade de sítios básicos expostos é reduzida devido a lixiviação dos cátions que se encontravam na superfície e na boca dos poros. Assim, os reagentes têm maior dificuldade para encontrar os sítios ativos dentro dos poros, ocasionando uma redução na atividade do catalisador (MARTINS et al., 2006).

Embora o etanol possua valores maiores de conversão em relação aos outros solventes, é o que mais influencia na variação das conversões ao longo dos reusos, pois inicialmente tem-se uma conversão de $\sim 93 \%$ e no terceiro uso esse valor cai para $\sim 50 \%$, tendo uma variação de $\sim 40 \%$, enquanto que para o toluol e acetonitrila essa variação acontece na faixa de 30 e $35 \%$, respectivamente.

A acetonitrila é um solvente polar aprótico e o toluol um solvente apolar. Logo, a acetonitrila promove uma maior separação das cargas e uma menor capacidade de solvatação 
dos ânions, uma vez que na reação de Knoevenagel há formação de um carbânion a partir da abstração de um próton do grupo metilênico ativado presente no cianoacetato de etila, fato este então responsável pela menor atividade da acetonitrila (CHAVES et al., 2016).

Outro ponto a destacar é a tendência mostrada pela curva de estabilidade, pois ao passo que para os solventes toluol e acetonitrila a conversão tende a alcançar um equilíbrio para a conversão do benzaldeído após o terceiro uso, para o etanol observa-se um comportamento contrário, já que a conversão tende a diminuir continuamente a medida que se reutiliza o catalisador (Figura 2.b).

A estabilidade estrutural da CTA-MCM-41 é muito frágil, pois independentemente do solvente utilizado na reação não há manutenção da estrutura, como é possível observar nos difratogramas de raios-X apresentados pela Figura 3. Ao empregar-se o tolueno como solvente verifica-se que a estrutura da MCM-41 é mantida após o primeiro uso, porém, após o terceiro uso obtém-se um difratograma característico de uma estrutura hexagonal, a qual não se encontra muito bem organizada.

Figura 3 - Difratogramas e espectros de FTIR das amostras de catalisador após primeiro e terceiro uso entre os solventes acetonitrila (a), etanol (b) e toluol (c).
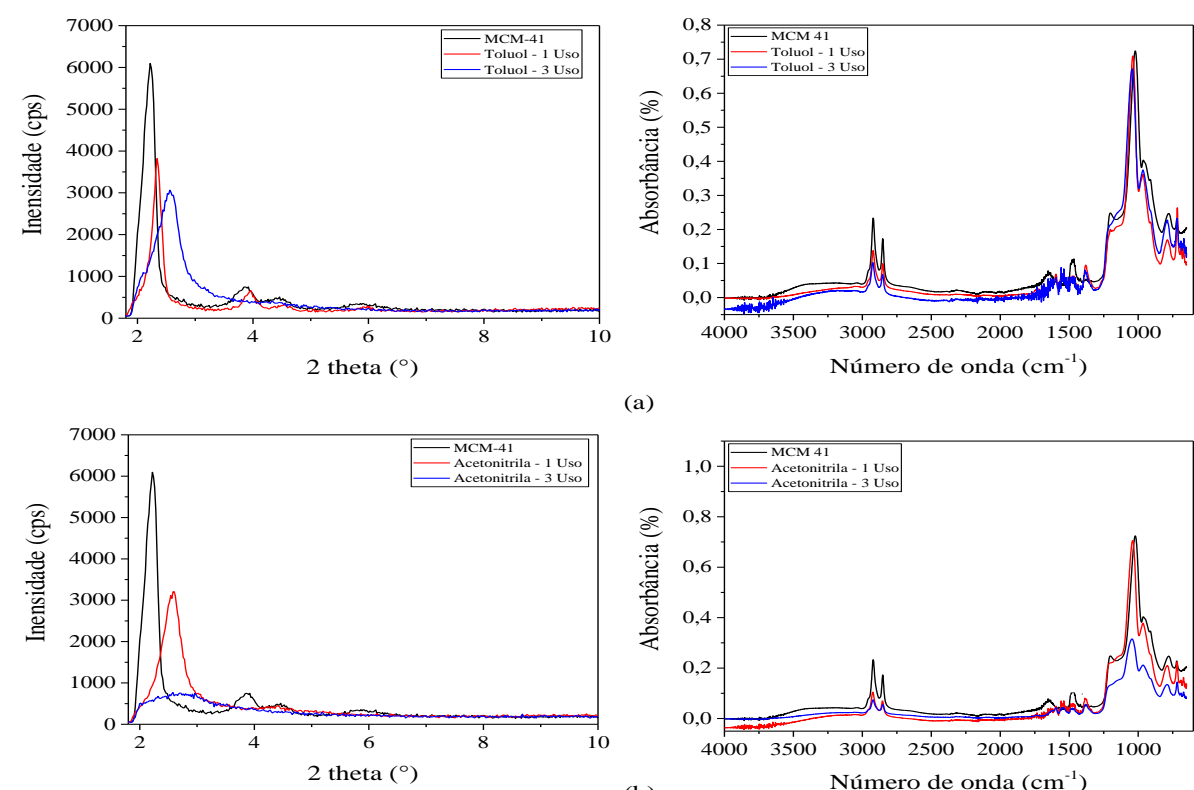

(a)
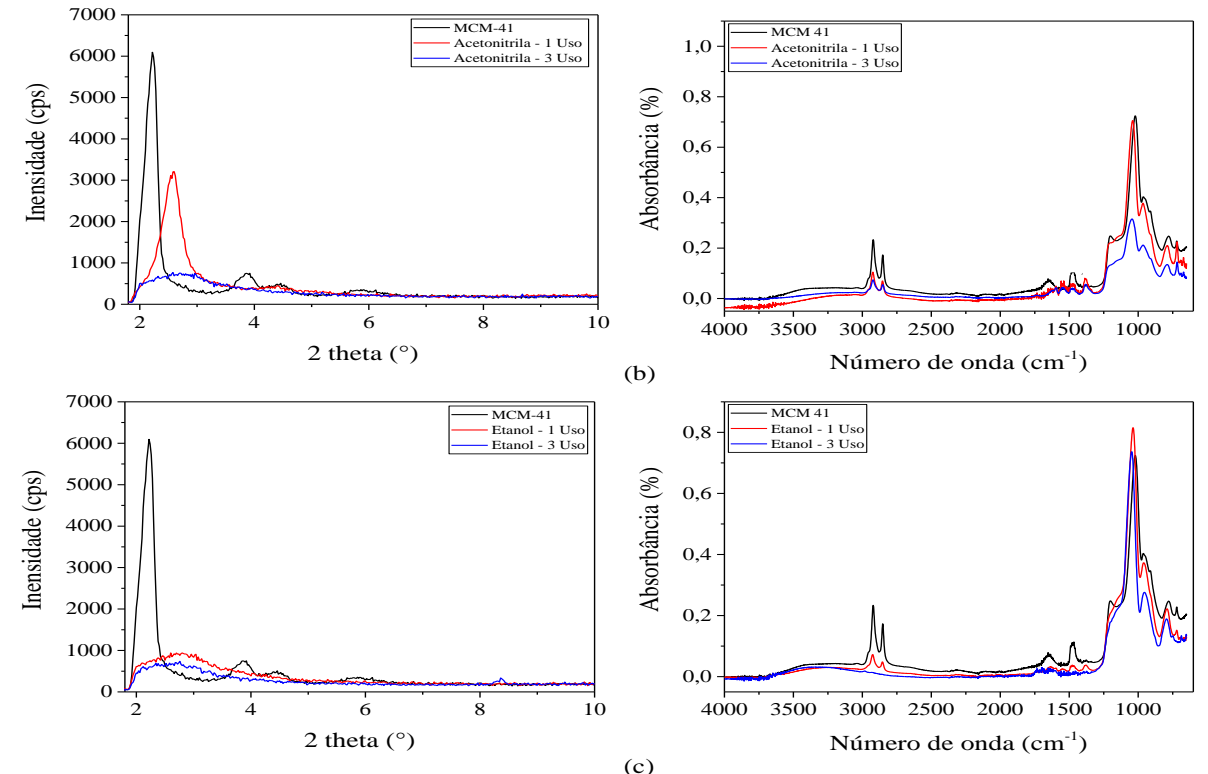

Conforme observa-se nos espectros de FTIR (Figura 3), ao passo que se reutiliza o catalisador, as bandas em torno de $3000 \mathrm{~cm}^{-1}$ referentes ao cátion orgânico, diminuem em 
função da utilização do catalisador, ou seja, independentemente do caráter do solvente empregado na reação, uma lixiviação do $\mathrm{CTA}^{+}$é decorrente. Essa lixiviação deve-se entre outros fatores, às propriedades físico-químicas do solvente (PIREZ et al., 2014).

De acordo com os espectros de FTIR, o etanol como solvente protônico, promove a total lixiviação do cátion e a desorganização da estrutura (Figura 3), consequentemente uma perda na atividade catalítica é reportada. Nesse sentido, o toluol seria o solvente mais estável pois é o que menos desestabiliza a estrutura da CTA-MCM-41 e que mantém uma conversão intermediária, este fato pode estar relacionado com o caráter apolar do toluol.

\section{REFERÊNCIAS}

ARAÚJO, J.A.; CARDOSO, D. Propriedades da sílica CTA-MCM-41 contendo metacrilatos e seu emprego na transesterificação de monoéster. 2013. 161 f. Tese (Doutorado em Engenharia Química) - Departamento de Engenharia Química, Universidade Federal de São Carlos, São Carlos, 2013.

ARAÚJO, J.A.; CRUZ, F. T.; CRUZ, I. H., CARDOSO, D.; Encapsulation of polymers in CTA-MCM-41 via microemulsion. Microporous and Mesoporous Materials, v. 180, p. 14- 21, 2013.

CHAVES, T. F.; CARVALHO, K. T. G.; URQUIETA-GONZÁLES, E. A.; CARDOSO, D. One-step synthesis of functionalized ZSM-12 zeolite as a hybrid basic catalyst. CrossMark, p. 2200-2213, 2016.

CHEN, C. Y.; LI, H. X.; DAVIS, M. E. Studies on mesoporous materials: I. Synthesis and characterization of MCM-41. Microporus Materials, v. 2, p. 17-26, 1993.

COSTA, J. A. S.; GARCIA, A. C. F. S.; SANTOS, D. O.; SARMENTO, V. H. V.; PORTO, A. L. M.; MESQUITA, M. E.; ROMÃO, L. P. C. A new functionalized MCM-41 mesoporous material for use in environmental applications. J. Braz. Chem. Soc., v. 25, p. 197-207, 2014.

LAGHAEI, M.; SADEGHIA, M.; GHALEIB, B.; DINARC, M. The effect of various types of post-synthetic modifications on the structure and properties of MCM-41 mesoporous silica. Progress in Organic Coatings, v. 90, p. 163-170, 2016.

MARTINS, L.; CARDOSO, D. Aplicação catalítica de peneiras moleculares básicas micro e mesoporosas. Q. Nova, v. 29, n. 2, p. 358-364, 2006.

OLIVEIRA, A. C.; MARTINS, L.; CARDOSO, D. Basic catalytic properties of assynthesized molecular sieves. Microporus and Mesoporus Materials. p. 206-213, 2009.

PIREZ, C., WILSON, K., LEE, A.F. An energy-efficient route to the rapid synthesis of organically-modified SBA-15 via ultrasonic template removal. Green Chemistry, v. 16 (1), p. 197-202, 2014.

VICENTE, J. G. P.; LIMA, P. M.; CARDOSO, D. Propriedades e avaliação catalítica da zeólita X nanométrica contendo cátions metilamônio. Q. Nova, v. 39, n. 6, p. 655-660, 2016.

VICENTE, J. G. P.; LIMA, P. M.; CARDOSO, D. Propriedades catalíticas da zeólita X nanométrica contendo cátions metilamônio substituídos, 2015.

ZHAO, X. S.; LU, G. Q.; WHITTAKER, A. K.; MILLAR, G. J.; ZHU, H. Y. Comprehensive study of surface chemistry of MCM-41 using 29Si CP/MAS NMR, FTIR, pyridineTPD, and TGA. The Journl of Physical Chemistry B, v. 101, p. 6525-6531, 1997. 